\title{
Designing a National Blended Learning Program for "Out-of-Field" Mathematics Teacher Professional Development
}

\author{
Merrilyn Goos \\ The University of Queensland, Australia \\ John O’Donoghue \\ University of Limerick \\ Máire Ní Ríordáin \\ University College Cork
}

See next page for additional authors

Follow this and additional works at: https://arrow.tudublin.ie/scschmatart

Part of the Education Commons, and the Mathematics Commons

\section{Recommended Citation \\ Goos, M. et al. (2020) Designing a National Blended Learning Program for "Out-of-Field" Mathematics Teacher Professional Development,ZDM: the international journal on mathematics education, 52(4) DOI: 10.1007/s11858-020-01136-y}

This Article is brought to you for free and open access by the School of Mathematics at ARROW@TU Dublin. It has been accepted for inclusion in Articles by an authorized administrator of ARROW@TU Dublin. For more information, please contact arrow.admin@tudublin.ie, aisling.coyne@tudublin.ie,gerard.connolly@tudublin.ie.

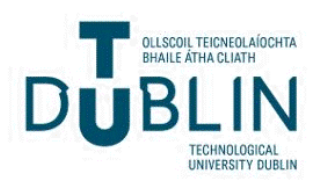


Authors

Merrilyn Goos, John O’Donoghue, Máire Ní Ríordáin, Fiona Faulkner, Tony Hall, and Niamh O'Meara

This article is available at ARROW@TU Dublin: https://arrow.tudublin.ie/scschmatart/304 


\title{
Designing a national blended learning program for "out-of-field" mathematics teacher professional development
}

\author{
Merrilyn Goos ${ }^{1} \mathbb{D} \cdot J^{\prime}$ John O’Donoghue ${ }^{1} \cdot$ Máire Ní Ríordáin $^{2} \cdot$ Fiona Faulkner $^{3} \cdot$ Tony Hall $^{4} \cdot$ Niamh O'Meara $^{1}$
}

Accepted: 23 January 2020 / Published online: 4 February 2020

(c) FIZ Karlsruhe 2020

\begin{abstract}
"Out-of-field" teaching refers to the practice of assigning secondary school teachers to teach subjects that do not match their training or education. This practice is an issue of concern in many countries around the world, and seems particularly prevalent in the teaching of mathematics. The aim of this paper is to analyse the design principles underpinning the development and delivery of a blended learning program of professional development for out-of-field teachers of secondary school mathematics in Ireland. Three theoretical frameworks inform our analysis of the blended learning design. The first identifies critical dimensions of blended learning environments as a boundary object facilitating coordination of face-to-face and computer-mediated instruction. The second framework conceptualises out-of-field teaching as a boundary-crossing event, and identifies contextual factors, support mechanisms and personal resources that influence identity formation in out-of-field teachers as they move between different disciplinary fields. The third framework identifies the structural and core features of effective teacher professional development: the form, duration and coherence of activities; nature of teacher participation; focus on (mathematical) content knowledge; and opportunities to engage in active learning. The original contribution made by our analysis is to integrate these frameworks within a blended learning context, with the aim of identifying the distinctive features of the Professional Diploma in Mathematics for Teaching afforded by this delivery mode.
\end{abstract}

Keywords Mathematics teacher professional development $\cdot$ Out-of-field teaching $\cdot$ Blended learning $\cdot$ Boundary crossing

\section{Introduction}

The development of online learning, e-learning and blended learning in mathematics education is a relatively new field of research. While it has been suggested that such technologies have the potential to transform classrooms, research into how and why this might occur typically lags behind the pace of digital change. Recent reviews of research in this field point to developmental trends worthy of further investigation. For example, Borba et al. (2016), drawing on

Merrilyn Goos

merrilyn.goos@ul.ie

1 EPI*STEM - National Centre for STEM Education, University of Limerick, Limerick, Ireland

2 School of Education, University College Cork, Cork, Ireland

3 School of Hospitailty Management and Tourism, Technological University Dublin, Dublin, Ireland

4 School of Education, National University of Ireland, Galway, Ireland their survey of international literature for ICME-13, identified mathematics teacher education involving blended learning as one of five trends representing both current activity and future possibilities. A similar trend was investigated in a previous issue of $Z D M$ which of focussed on online mathematics teacher education, with the guest editors concluding that "much remains unclear about teacher learning and teachers' professional growth through participating in online professional development programs" (Borba \& Llinares, 2012, p. 697).

Our broad aim in this paper is to shed some light on the processes and principles involved in designing a blended professional learning program for out-of-field teachers of secondary school mathematics. "Out-of-field" teaching refers to the practice of assigning teachers to teach subjects that do not match their training or education (Ingersoll, 2002). While the phenomenon of out-of-field teaching is widespread, the reasons for and consequences of such practices are not well understood and research into the distinctive professional learning needs of out-of-field teachers has only 
recently begun to emerge (e.g., Faulkner et al., 2019; Hobbs \& Törner, 2019; Ní Ríordáin et al., 2017).

In this paper, we retrospectively analyse the evolution of design principles informing a national professional learning program for out-of-field teachers of mathematics in Ireland, the Professional Diploma in Mathematics for Teaching (PDMT). The paper presents the blended learning model employed by the PDMT and examines how this approach contributed to the program's distinctive character. In the following sections we outline the background and context of out-of-field teaching of mathematics in Ireland and describe the development and evolution of the PDMT from 2012 to 2019 , corresponding to the period of the government contract for its delivery. We then analyse the design features of the PDMT using three theoretical frameworks. The first examines definitions, dimensions, and rationales for blended learning. The second framework characterises out-of-field teaching as a boundary-crossing event (Hobbs, 2013), and the third looks to effective teacher professional development using structural and core features (Garet et al., 2001). The research question guiding the analysis is: How does a blended learning environment contribute to effective professional learning for out-of-field teachers of mathematics?

\section{Background and context}

The phenomenon of out-of-field mathematics teaching was identified as a significant contributory factor in an underperforming school mathematics sector in Ireland at the beginning of the 21 st century, and a potential obstacle to maximising outcomes from then current reforms in post-primary school mathematics ${ }^{1}$ (Ní Ríordáin \& Hannigan, 2009). The Teaching Council of Ireland was established in 2006 to promote and regulate standards for the school teaching profession in Ireland and to maintain a register of qualified teachers. Currently in Ireland, newly registered post-primary mathematics teachers must meet specific standards, achieved through degree level studies in mathematics, and have an initial teacher education (ITE) qualification. This qualification can be achieved through a recognised concurrent (undergraduate) or consecutive (postgraduate) program.

Studies by Ní Ríordáin and Hannigan (2009) and previously by Cosgrove et al. (2004) mapped the situation as regards out-of-field teaching in mathematics in the Irish context. Based on a survey of teachers of mathematics

\footnotetext{
${ }^{1}$ In Ireland the post-primary education sector comprises secondary, vocational, community and comprehensive schools. Secondary schools are privately owned and managed. Vocational schools are state-established and administered by Education and Training Boards (ETBs), while community and comprehensive schools are managed by Boards of Management of differing compositions.
}

conducted in conjunction with Ireland's participation in PISA 2003, a sample of 1273 teachers of mathematics in 143 post-primary schools giving 856 respondents indicated that $28 \%$ of teachers of mathematics were "out-of-field". This was based on a historical and weakly framed view of qualified teacher status for mathematics teaching: teachers were considered to be unqualified with respect to mathematics (i.e., out-of-field) if they did not have mathematics as a major component in their undergraduate degree (Cosgrove et al., 2004). In their later study, Ní Ríordáin and Hannigan used a more explicitly strong definition of "qualified mathematics teacher" promulgated by the new Teaching Council (2009), which stipulated that teachers must:

- Have studied Mathematics as a major subject in the degree extending over at least 3 years and of the order of $30 \%$ at a minimum of that period;

- Provide details of the degree course content to show that the breadth and depth of the syllabi undertaken are such as to ensure competence to teach Mathematics to the highest level in post-primary education; and

- Provide explicit evidence of standards achieved in degree studies in Mathematics with at least an overall Pass result in the examinations in Mathematics.

Ní Ríordáin and Hannigan (2009) found 48\% of the 324 post-primary teachers of mathematics in their study were out-of-field in mathematics, since they did not possess the qualifications for teaching mathematics stipulated by the Teaching Council.

The convergence of thinking around the central role of teachers and quality of teaching and evidence about out-offield mathematics teaching resulted in the Irish Government Department of Education and Skills (DES) issuing a Request for Tender (RFT) to Upskill Teachers of Mathematics in December 2011. The winning bid was developed by the National Centre for Excellence in Mathematics and Science Teaching and Learning (NCE-MSTL), now EPI*STEM, at the University of Limerick (UL), and the relevant departments in the National University of Ireland, Galway (NUIG), and submitted by the UL/NUIG-led consortium of 13 Irish higher education institutions. The PDMT, delivered in a blended learning format, admitted its first cohort of teachers in September 2012 and the DES continues to fund the diploma as part of the national strategy to support the implementation of the new mathematics curriculum and improve standards in mathematics education in post-primary schools. Six cohorts, or around 1100 teachers, have participated in the program since its inception with all teachers' tuition fees paid by the DES. The PDMT is closely aligned with the needs of out-of-field teachers of mathematics, the new mathematics curriculum, and the requirements of the Irish Teaching Council for mathematics teaching and must be seen as a 
significant element in the reform of the national mathematics curriculum for post-primary education in Ireland.

\section{Development and evolution of the PDMT program}

The PDMT is a 2-year, part-time, blended learning program worth 75 ECTS credits $^{2}$ that addresses the lack of mathematics content knowledge and mathematics teaching qualifications among serving teachers of mathematics. Participants teach full-time in schools while completing the PDMT in the evenings, week-ends, and summer vacation. The Director of EPI*STEM (formerly the NCE-MSTL) acts as Course Director ${ }^{3}$ and is chair of the course team, comprising members of faculty at UL/NUIG. The National Program Coordinator and a Teaching Coordinator support the course team on a full-time basis. Under the terms of the DES contract, a Monitoring Group comprising DES officials from the Teacher Education Section and the Schools' Inspectorate and members of the course team monitors the program. Successful participants, who are already registered qualified post-primary teachers in (an)other subject(s), have mathematics added to their registration by the Teaching Council on completion of the program.

\subsection{PDMT rationale and goals}

The program design reflects specific demands set forth in the RFT document, which could not be varied. In particular, there was the non-negotiable stipulation that graduates would meet the Teaching Council requirements for fully qualified in-field secondary mathematics teachers. The program also had to be accessible to out-of-field teachers of mathematics throughout Ireland, a requirement that necessitated a blended learning approach combining online and face-to-face elements. The program design is guided by and seeks to incorporate a small number of important principles that are fundamental to our view of mathematics teacher education: strong mathematical knowledge is essential for good teaching; good mathematics pedagogy is built on a strong mathematical knowledge base; pedagogical content

\footnotetext{
${ }^{2}$ ECTS refers to the European Credit Transfer System representing the workload and defining learning outcomes of a given course or program. 1 ECTS typically corresponds to between 20 and $25 \mathrm{~h}$ of student learning activity, including, for example, class contact time, reading and research, and assessment preparation and completion.

${ }^{3}$ In Ireland a university degree or diploma is referred to as a course and its constituent elements (typically semester-long subjects) as modules. In this paper we have retained the module terminology when describing the elements of the PDMT but henceforth refer to the PDMT as a program.
}

knowledge (PCK) and subject content knowledge (SCK) are not independent and should be developed in tandem (Ball et al., 2008; Heid et al., 2015; Rowland et al., 2005; Shulman, 1986). Accordingly, the overarching goals are to ensure that successful candidates have acquired the extensive and complex knowledge base that is necessary for effective mathematics teaching at secondary school level, have demonstrated an ability to integrate this mathematical knowledge for teaching into professional practice as mathematics teachers, and have become oriented towards lifelong learning in mathematics for teaching.

Several studies evaluating the effectiveness of the PDMT have been completed during the lifetime of the program, and others are in progress. These evaluations comprise formal research studies, regular university surveys that invite PDMT participants to evaluate the program, and informal feedback from members of the DES Monitoring Group. While it is beyond the scope of this paper to discuss the findings of such studies, further details can be found in Faulkner and O’ Meara (2018), Faulkner et al. (2019), Goos et al. (2019), Lane and Ní Ríordáin (2019), and Ní Ríordáin et al. (2017).

\subsection{Program structure and elements}

The PDMT is packaged in ten mathematics content modules delivered online with additional face-to-face and online support and two mathematics pedagogy modules delivered faceto-face (Table 1). The mathematics modules, each worth 6 ECTS credits, are presented in $30 \mathrm{~h}$ blocks in six-week sessions (24 lectures, 6 tutorials) and cover topic areas such as calculus, algebra (including linear algebra and number theory), probability, statistics, geometry, problem solving and modelling, and history of mathematics. The two mathematics pedagogy modules, worth 6 and 9 ECTS credits respectively, are spread over a full academic year and summer. Attendance for these latter modules is compulsory at five 3-h workshops and a week-long summer school. The mathematics pedagogy modules focus on developing pedagogical content knowledge and each is explicitly linked to the corresponding mathematics content module so that PCK and SCK can be developed together. A variety of assessment types is employed, including written assignments, workshop participation, projects, mathematics problem sets, and supervised examinations. One of the pedagogy modules also requires participants to complete a supervised action research project on their practice in the classroom.

When the PDMT was launched in September 2012, the program was delivered nationally in a blended learning mode through local nodes in partner institutions located throughout Ireland, in face-to-face and/or on-line modalities. Initially, mathematics lectures were broadcast in real-time on the appointed evenings by the lead lecturer from a primary site to secondary sites. Secondary sites were attended by 
Table 1 PDMT program structure and modules

\begin{tabular}{ll}
\hline Year 1 & Year 2 \\
\hline Calculus 1 & Statistics \\
Calculus 2 & Geometry \\
Algebra 1 & History of mathematics \\
Algebra 2 & Calculus 3 \\
Probability & Mathematical modelling \\
Mathematics pedagogy 1 (3 workshops on calculus, algebra and & Mathematics pedagogy 2 (2 workshops \\
number, probability) & on statistics, geometry and trigonom- \\
& etry) \\
Mathematics pedagogy summer school & Action research project \\
\hline
\end{tabular}

local mathematics lecturers who mediated the live transmissions in face-to-face interaction with participants and conducted tutorials at the site. All lectures were recorded live and posted to the website later for individual viewing from home/school. After the first year of the program, when a full suite of lectures had been video-recorded, the blended format changed to make use of these pre-recorded lectures for delivery of mathematics modules, supplemented by faceto-face tutorials. Additional supports available to participants include:

- Module booklets that develop a strong narrative structure around the progression of the mathematics content, lecture by lecture;

- Lecture notes/slides made available online in advance of the lecture;

- Specially developed screencasts and applets available online for each lecture for selected difficult topics;

- A facility to book individual additional tutor time online;

- Monitored chat room during individual screening of all mathematics lecture videos;

- Online tutorials for topics arising in the chat room.

\section{Theoretical frameworks}

The process of critical analysis of the PDMT's design principles, the core of this study, is supported and facilitated by the use of selected theoretical frameworks. Two of the frameworks, one examining features of effective professional learning programs (Garet et al., 2001) and the other theorising teaching out of field as a boundary crossing event (Hobbs, 2013), enhance our understanding of the phenomenon of out-of-field teaching and the challenges posed for teachers who are expected to move between infield and out-of-field practices. However, these frameworks take no account of blended learning as a foundational element in program design or its impact. Consequently, this section begins with a discussion of blended learning in higher education and teacher education contexts in order to establish the features of, and rationale for, blended learning environments.

\subsection{Blended learning}

In their introduction to a previous issue of $Z D M$ focusing on online mathematics teacher education, Borba and Llinares (2012) identified several conceptual and analytical challenges for research into the design of online learning environments. They noted in addition that hybrid and blended learning environments, whether these operate solely in a distance learning mode or combine face-to-face interaction with an online component, present unique design challenges, affordances and constraints. There is currently little published research on mathematics teacher education using blended learning. One example that illustrates the possibilities of this approach was described by Borba et al. (2016) in their ICME-13 survey of international literature in on blended learning, e-learning and mobile learning in mathematics education. This was a Canadian "mathematics-forteachers" elementary teacher education course, in operation for some time, that had begun experimenting with blended learning by replacing large lectures with online mathematical activities that the pre-service teachers complete before attending smaller face-to-face workshops. A goal of the course was to provide experiences that help participants to experience mathematics in new and surprising ways. The online resources available to participants comprised a variety of formats (e.g., classroom videos, simulations, games) and mathematical topics. Borba et al. speculated that such an instructional model might change classroom dynamics and blur the boundary between face-to-face and online interaction. While there are some parallels between this Canadian program and the PDMT, in that participating teachers (pre-service or in-service) lack a strong mathematics background, there also are many differences. In particular, the PDMT is a national program operating across multiple higher education institutions, with participants geographically dispersed and studying "after hours" — in both online and face-to-face modes_-while teaching full-time in schools. 
These distinctive features of the PDMT led us to examine the broader higher education literature on blended learning in order to identify design principles that could inform our theorisation of the PDMT's blended learning environment.

Many different but related characterisations of blended learning in higher education are available in the literature. For example, Alammary et al. (2014) discussed a wide range of definitions of blended learning and their implications for design approaches. However, they noted that all the definitions they reviewed involve the integration of different instructional methods coming from two historical models: traditional face-to-face learning and computer-mediated learning. They proposed that blended learning courses are those that:

1. Thoughtfully integrate different instructional methods such as: lecture, discussion group, self-paced activity; and

2. Contain both face-to-face and computer-mediated portions (p. 443).

Graham (2006) reviewed common definitions of blended learning, including those that refer to combining only delivery media and instructional methods. However, he insisted that a definition of blended learning must acknowledge the historical emergence of this approach as combining two separate models of teaching and learning: face-to-face instruction and computer-mediated instruction. More recently, Graham (2013) proposed that it might be helpful to think of the term "blended learning" as a boundary object (Star \& Griesemer, 1989), or an element that can have different meanings within the worlds it connects while enabling people in those separate worlds to work together. Extending this theoretical idea even further, we propose that a blended learning environment facilitates boundary crossing between face-to-face and computer-mediated instructional modes for both learners and instructors. This theorisation of blended learning is especially useful for our analysis of the PDMT and other forms of boundary crossing supported by the program (e.g., teachers crossing between in-field and out-offield disciplines; mathematicians and mathematics educators crossing between professional communities). We take up the notion of boundary crossing at several points throughout our analysis of the PDMT, and return to this idea in the Discussion and Conclusion.

Osguthorpe and Graham (2003) argued that both faceto-face and fully online distance learning paradigms have strengths and weaknesses that can complement each other in a blended learning environment. For example, fully online programs might offer only limited, or less spontaneous, human interaction, leading to feelings of isolation that can reduce student motivation and increase the risk of attrition. On the other hand, online programs incorporate

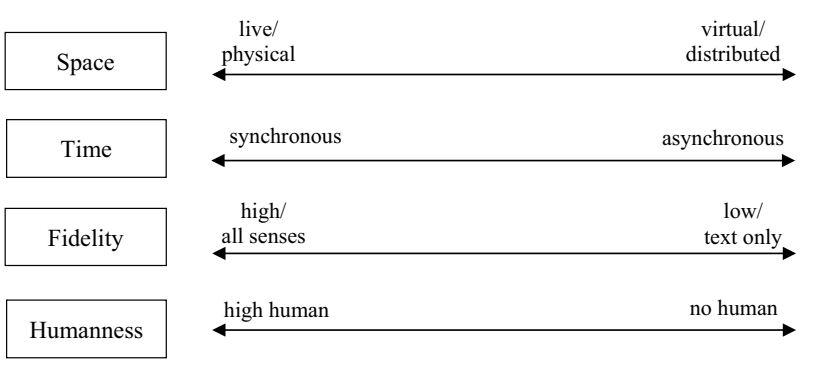

Fig. 1 Dimensions of interaction in face-to-face and distributed learning environments (adapted from Graham, 2006)

time flexibility that facilitates the participation of working adults, such as school teachers. Graham's (2006) framework for blended learning refers to four dimensions of interaction that can occur in both face-to-face and distributed learning environments: space, time, fidelity, and humanness (Fig. 1). Historically, distributed learning environments operated at the right hand end of these dimensions, and were exemplified by text-based distance education programs that emphasised learner-material interactions. In contrast, face-to-face environments operated at the left hand end of these dimensions and prioritised human interaction between teachers and learners, and amongst learners. However, digital technologies enable blended learning environments to incorporate many of the advantages of the face-to-face instructional landscape. For example, the computer-mediated element of a blended learning environment can change the constraints inherent in the time dimension by incorporating interaction that is delayed/asynchronous (e.g., bulletin board, online video) and real-time/synchronous (e.g., live chat, online tutorial). Also, the fidelity of a learning experience is no longer limited by access only to text-based materials, but is enhanced by use of interactive video and web-based resources as well as online software and applets available on portable devices. On the humanness dimension, human-computer interfaces simulate within a virtual space the intimacy of the physical classroom.

Osguthorpe and Graham (2003) proposed six possible goals for designing blended learning environments: (1) improving pedagogical richness, (2) facilitating access to knowledge, (3) supporting social interaction, (4) developing learners' personal agency, (5) achieving cost effectiveness, and (6) enabling ease of revision. However, Graham et al. (2005) found that improved pedagogy, access/flexibility, and cost effectiveness were the most commonly cited reasons for instructors choosing a blended learning design.

Pedagogical richness is enhanced in a blended learning environment that supports active learning, peer interaction, access to a wide range of resources, and opportunities to apply new knowledge in the workplace. Access and flexibility are key enablers of participation by mature learners 
who have multiple professional and family commitments, and a desire for self-directed learning that involves a high level of human interaction-whether face-to-face or virtual. While cost effectiveness has a financial dimension, it also refers to the significant affordances of a blended learning design_-particularly through its online component-for reaching large numbers of participants who are geographically dispersed. Such affordances are of particular interest to teachers and teacher educators engaged in large-scale professional development. For example, Borko et al. (2009) noted that digital technologies enable professional development providers "to draw on resources not available locally, offer 'just-in-time' work-embedded support, and accommodate individual teachers' busy schedules" (p. 5).

In contemporary educational technology and educational design research, the concept of infrastructuring (Penuel 2015,2019 ) has also emerged as a key concern and challenge, particularly in terms of the design and development of innovative educational interventions that achieve impact at scale. Scalable design and achieving systemic impact is a major goal for the design of innovations and technologies in education today (McKenney, 2018). Infrastructuring refers to the multi-level nature of successful design of blended learning that is effectively cross-sectional and integrates the key domains of educational research, policy and practice. However, the nature of infrastructuring in context can be amorphous, and challenging to define. All of these features of blended learning, incorporating dimensions of interaction, affordances of a blended environment, and the need to consider scalability and impact, were critical to the design of the PDMT.

\subsection{Out-of-field teaching}

Out-of-field teachers have been found to suffer from a lack of confidence, stress and feelings of inadequacy (du Plessis, 2016). du Plessis (2015) found that out-of-field teachers' lack of pedagogical content knowledge and subject matter knowledge was fundamental to these concerns, and that the out-of-field phenomenon hampered development of a professional identity in an out-of-field subject.

In an Australian study based on data obtained from a sample of teachers of science and mathematics, Hobbs (2013) investigated the impact of out-of-field teaching on teachers engaged in this practice. She theorised out-of-field teaching as a boundary-crossing event, and she proposed the Boundary Between Fields Model (BBF) to incorporate groups of factors that have a bearing on teacher identity formation. The Hobbs study is underpinned by a sociocultural view of boundaries in that "a boundary can be seen as a sociocultural difference leading to discontinuity in action or interaction" (Akkerman \& Bakker, 2011, p. 133). Hobbs explained that out-of-field teachers encounter a boundary when there is a discontinuity between the "practices and perspectives" (p. 274) required when teaching the subject in which they are not qualified. These discontinuities can be overcome by re-establishing action or interaction, which process itself is seen as an important resource for learning at the boundary leading to (professional) learning. The learning potential at the boundary includes identity development and is elaborated in the definition offered by Akkerman and Bakker (2011): "We employ the term learning in a very broad sense, including new understandings, identity development, change of practices, and institutional development" (p. 142).

Hobbs (2013) identifies contextual factors, support mechanisms and personal resources that influence identity formation in out-of-field teachers as they move between different disciplinary fields. Contextual factors include such considerations as geographical region (e.g., rural, urban); nature of school (e.g., designs, size); and state issues (e.g., governance, policies and practices). Support mechanisms include formal courses or school supports such as mentor/ coaches in the out-of-field subject (e.g., mathematics); selfconstructed materials and resources for teaching; and supports sought by the teacher on her/his own initiative (e.g., specific help sought from expert colleagues or significant others). Hobbs summarises personal resources as "adaptive expertise, knowledge, and confidence and commitment as dispositions" (p. 288). A teacher's ability to cope with the adjustments demanded by out-of-field teaching can be thought of as their adaptive expertise. The knowledge factor specifically relates to teacher knowledge in Shulman's (1986) sense. Teacher knowledge(s) in its multiple dimensions is a major factor influencing teachers in their new role. Confidence and commitment are dispositions that derive from or are associated with the other important factors but are no less important than these.

The BBF model of Hobbs (2013) provides a template for considering the efficacy of the PDMT program as a vehicle for professional learning for out-of-field teachers of mathematics in Ireland. Furthermore, the model intersects and resonates with our chosen model of professional development for teachers (Garet et al., 2001).

\subsection{A teacher professional development framework}

Garet et al. (2001) proposed a model of teacher professional development based on a large American study, of mainly science and mathematics teachers. The aim of the study was to compare the effects of different characteristics of professional development on teachers' learning, an area of study that is underdeveloped and under-reported in the literature. This framework identifies structural and core features of effective teacher professional development. The structural features of the framework refer to characteristics of the design of the professional 
Table 2 Selected features of contributing frameworks

\begin{tabular}{lll}
\hline $\begin{array}{l}\text { Blended learning: } \\
\text { Dimensions and reasons for use } \\
\text { (Graham et al., 2005; Graham, 2006) }\end{array}$ & $\begin{array}{l}\text { Out-of-field teaching: } \\
\text { Factors influencing teacher } \\
\text { identity formation } \\
\text { (Hobbs, 2013) }\end{array}$ & $\begin{array}{l}\text { Teacher professional devel- } \\
\text { opment: } \\
\text { Characteristics of effec- } \\
\text { tive programs (Garet et al., } \\
2001)\end{array}$ \\
\hline Dimensions & Context & Structural features \\
Space & Geographical region & Form of activity \\
Time & School size & Duration of activity \\
Fidelity & State governance structures, & Collective participation \\
pramanness & Support mech, policies & \\
Reasons for use & Provided & Core features \\
Improve pedagogy & Self-sought & Content knowledge \\
Increase access and flexibility & Self-constructed & Active learning \\
Cost-effectiveness at scale & Personal resources & \\
& Adaptive expertise & \\
& Teacher knowledge & \\
& Dispositions & \\
\hline
\end{tabular}

development activities and focus on form and duration of activities and nature of teacher participation. The core features are concerned with the degree to which the activity focuses on developing teachers' content knowledge, opportunities to engage in active learning, and the coherence of the professional development program.

Garet et al. (2001) elaborate on structural features as follows: the form of activity includes all traditional types such as workshops, conferences, institutes, and nontraditional types such as mentoring, coaching and study groups; duration is associated with sustained activity over time; and collective participation by groups of teachers is valorised. The authors offer a similar fine-grained elucidation of the three core features of the framework. Considerations related to content knowledge include balance between content knowledge, pedagogical content knowledge (PCK), and general pedagogy. Opportunities to engage in active learning centre on observing classes/ teachers, to be observed teaching, implement new ideas, review student work, lead a discussion, and write presentations. Fostering coherence can involve linking the activity with teachers' previous professional development experiences and future goals, aligning the activity with national or local standards and assessments, and creating opportunities for professional communication with colleagues.

The professional development framework of Garet et al. (2001) seems particularly appropriate for a task that relates specifically to a blended learning program design that seeks to exploit approaches from two different pedagogical traditions, face-to-face learning and computermediated learning.

\section{A multiple-lens view of the PDMT as a blended professional learning experience}

Our methodological task now is to combine the multiple theoretical frameworks (summarised in Table 2) in a meaningful way that highlights distinctive features of the PDMT that arise in a blended learning context and contribute to successful professional learning for out-of-field teachers of mathematics.

The PDMT's blended learning format functions on a number of levels that penetrates the other frameworks, underlining the fact that blended learning is not simply a mode of delivery but a source of affordances for teaching and learning. These affordances are examined in the next sections, which develop a multiple-lens view of the PDMT as a blended professional learning experience. The analysis draws on our considerable experience of serving in various key roles in the PDMT since its inception: collectively our author team represents course directors, design team, National Program Coordinator; pedagogy leader; leader of the Irish language version of the program; and members of the program Monitoring Group. The continuous involvement by some members of this group ensures that there is a strong historic memory to draw on from an "insider perspective" while this is balanced by a more "arms length" perspective of others who have come more recently to roles within the program.

Informing our analysis is an array of documents that were available to us. These include design proposals, the DES tender, university submissions seeking program 
approval, the submission to the Teaching Council, interim student program evaluations, published evaluations, reports to the Monitoring Group established under the terms of the DES contract, minutes of Monitoring Group meetings, and a published case study of the PDMT (Faulkner et al., 2019). A large collection of program and module documents augments this collection.

\subsection{The PDMT through the blended learning lens}

The PDMT format employs a characterisation of blended learning customised for use with this program. This format evolved in a pragmatic way as the PDMT personnel gained experience, and in retrospect, may be described by reference to Graham's (2006) four critical dimensions of interaction (Fig. 1): space, time, fidelity, and humanness.

The space dimension of the PDMT involves a combination of separate live/physical spaces and virtual/distributed spaces. The virtual spaces comprise video-recorded university mathematics lectures streamed on designated evenings and then posted to the course website to enable later repeated viewing, as well as various online tools that facilitate distributed interactions between tutors and PDMT participants. Physical spaces comprise face-to-face mathematics tutorials provided at numerous venues nationwide in order to supplement the video lectures, week-end pedagogy workshops and the annual pedagogy summer school, and participants' own classrooms in which they teach and conduct the action research component of the PDMT course.

The time and fidelity dimensions allow synchronous and asynchronous distributed interaction with a high level of fidelity involving more than text-based materials. The positioning of the program with respect to the humanness dimension has changed over time. Initially, human interaction was present in all elements of the program; for example, mathematics lectures, broadcast from the primary site, were mediated in person at secondary sites by local mathematics lecturers who also provided face-to-face interactions at particular points during the lecture when live transmission was paused and via tutorials afterwards. The ratio of face-toface to online interaction has since then evolved to roughly 1:2 as a suite of video-recorded lectures was developed and improvements in technology made it possible to offer live online tutorials. Nevertheless, we maintain that fully human interaction is important for the mathematics pedagogy elements of the program, which are always offered in face-toface mode.

\subsection{The PDMT through the teacher professional development lens}

An analysis of the PDMT program design is presented in this section using the teacher professional development framework of Garet et al. (2001) as a retrospective lens. This framework is built on two constructs, structural and core features related to program design. Structural features refer to general design issues but focus on form and duration of activities and the nature of teacher participation. In the Request for Tender document issued by the DES, the Irish Minister for Education and Skills stipulated the requirements for the form of the PDMT. These requirements were such that participants had to successfully complete a university validated graduate program (75 ECTS) presented in a blended learning format. It was expected that participants would complete the PDMT in 2 years, and no more than 3 years, of part-time study. Eligible participants had to be registered secondary teachers qualified in a discipline other than mathematics, employed in an Irish secondary school, and teaching at least one mathematics class (i.e., teaching mathematics out-of-field). Graduates were required to meet the accreditation requirements of the Irish Teaching Council, the regulatory body for the teaching profession.

Thus, the normal duration of the PDMT is 2 years parttime study. The PDMT is designed for out-of-school-time participation by teachers with program activities scheduled for evenings, weekends, school holidays, and summer vacation. Participating teachers were not released from normal teaching duties and received no additional in-school mathematics support, despite significant additional demands on their time.

The PDMT provides for nationwide participation by teachers, as stipulated in the DES Request for Tender, by employing a blended learning format combining face-toface and online modes delivered through a national consortium of higher education institutions. Teacher participation is facilitated through use of pre-recorded lectures made available online at a designated time for home viewing and subsequently posted to the course website to allow for ongoing access and repeated viewing. These lectures are interspersed with interactive mathematical tasks, to simulate face-to-face delivery where the lecturer directly engages with students and their responses. Other forms of teacher participation include lecture notes, face-to-face tutorials and workshops at higher education institutions around the country, moderated asynchronous online discussion forums and synchronous individual and group online tutorials for each mathematics content module, and a large collection of screencasts and applets for specific topics. While collective participation by groups of teachers is an important element in the Garet et al. (2001) framework, no formal provision is made to develop such activity in the PDMT design, although informal groupings were known to exist in various cohorts and are encouraged by the course team. A primary goal for the design team was to ensure that at least one teacher from every post-primary school in the country joined the program. 
Although it would be preferable for more than one teacher per school to participate in order to facilitate professional collaboration in the school context, the DES imposed limitations on the numbers of teachers it would fund to enrol in each cohort of the PDMT. In practice, this meant that priority had to be given to recruiting as many schools as possible rather than multiple teachers in a smaller set of schools. Even so, anecdotal evidence suggests that more than one teacher in many schools were upskilled through participation in the program.

We now turn to consideration of the PDMT program's core features. The content is packaged in twelve modules comprising ten mathematics modules and two mathematics pedagogy modules, and includes compulsory attendance at 1 week-long summer school. The quantum of mathematics (60 ECTS credits) and selection of topics is shaped by the DES tender and the non-negotiable Teaching Council requirement that PDMT graduates meet the same or equivalent requirements for mathematics teaching as fully qualified in-field secondary mathematics teachers. The PDMT anticipates varying mathematical needs and is tailored to them in a number of ways: for example, through recognition of prior learning through other academic or professional development courses; by provision of a suite of online mathematics learning supports; and flexible pathways through the program for those experiencing difficulties.

The blended learning format encourages active learning in the face-to-face and computer-mediated modalities. All mathematics content lectures include interactive sessions and these are continued and supplemented in the face-to-face tutorials and course assignments. Similarly, online tutorials and supports such as screencasts and applets are designed to engage participants in problem solving and investigations. The active learning theme runs through the action research projects, mathematics pedagogy workshops and summer school where teachers are challenged to engage actively by the nature and design of assignments and activities. However, no systematic attention is devoted to meaningful analysis of teaching and learning in the teachers' own classrooms in the ways envisaged by Garet et al. (2001).

The PDMT is consistent with the national mathematics curriculum reform and the Teaching Council's standards for accrediting teacher education programs and registering teachers. This consistency strongly enhances its coherence as a professional development program. These national standards and frameworks communicate clear expectations to schools and teachers about requirements for curriculum delivery and teacher quality, and completion of the PDMT has enhanced graduates' prospects for gaining employment contracts as fully qualified mathematics teachers. Participants may experience another dimension of coherence identified by Garet et al. (2001), involving opportunities for professional communication with colleagues engaged in similar initiatives, but this is not an explicit goal of the program.

\subsection{The PDMT through the out-of-field teaching lens}

A closer examination of the PDMT program using Hobbs's (2013) Boundary Between Fields model offers further opportunity for insights about the efficacy of the program and its blended learning design. A small number of contextual factors are relevant here because they have a bearing on the nature and outcome of out-of-field teachers' engagement with the PDMT. The size of the commitment in terms of the quantum of mathematics content, which was dictated by official policy in relation to qualified mathematics teacher status, was daunting for teachers for whom mathematics teaching was not a first career choice. The commitment, measured in duration of program ( 2 years part-time), and time devoted to study and travel was considered to be quite onerous by many and resulted in dispositional issues for some such as lack of perseverance or willingness to engage. These issues were compounded by the fact that for many of the participating teachers the voluntary nature of participation was undermined by a pressing need to secure ongoing employment in their schools. Such issues were confronted as the program evolved and were largely addressed by exploiting flexibilities in the program design and adding various online learner supports (e.g., online tutorials, screen casts, and lecture notes).

Multiple support mechanisms were devised and implemented in response to identified needs as the PDMT evolved. In this paper we distinguish between two types of support, program supports and school supports. School supports, such as provision of mentoring by expert teachers and release time for study and for trying out new classroom practices (Hobbs, 2013), are not generally available to PDMT participants or to any other teachers participating in professional development programs in Ireland. Program supports may be grouped into three broad categories as follows: study supports (e.g., lecture videos and lecture notes posted online, face-to-face and online tutorials, screencasts, applets, past examinations and worked solutions); social contacts (e.g., face-to-face tutorials, moderated chat room, personal bookable online tutorials, staffed online office hours, online access to National Program Coordinator); and online program information and navigation aids (e.g., Student handbook, Program calendar, module booklets).

Personal resources of the teacher who is moving from in-field to out-of-field teaching in mathematics (or other subjects) are a significant component of the Boundary Between Fields model. Hobbs (2013) lists these as adaptive expertise and knowledge, and confidence and commitment 


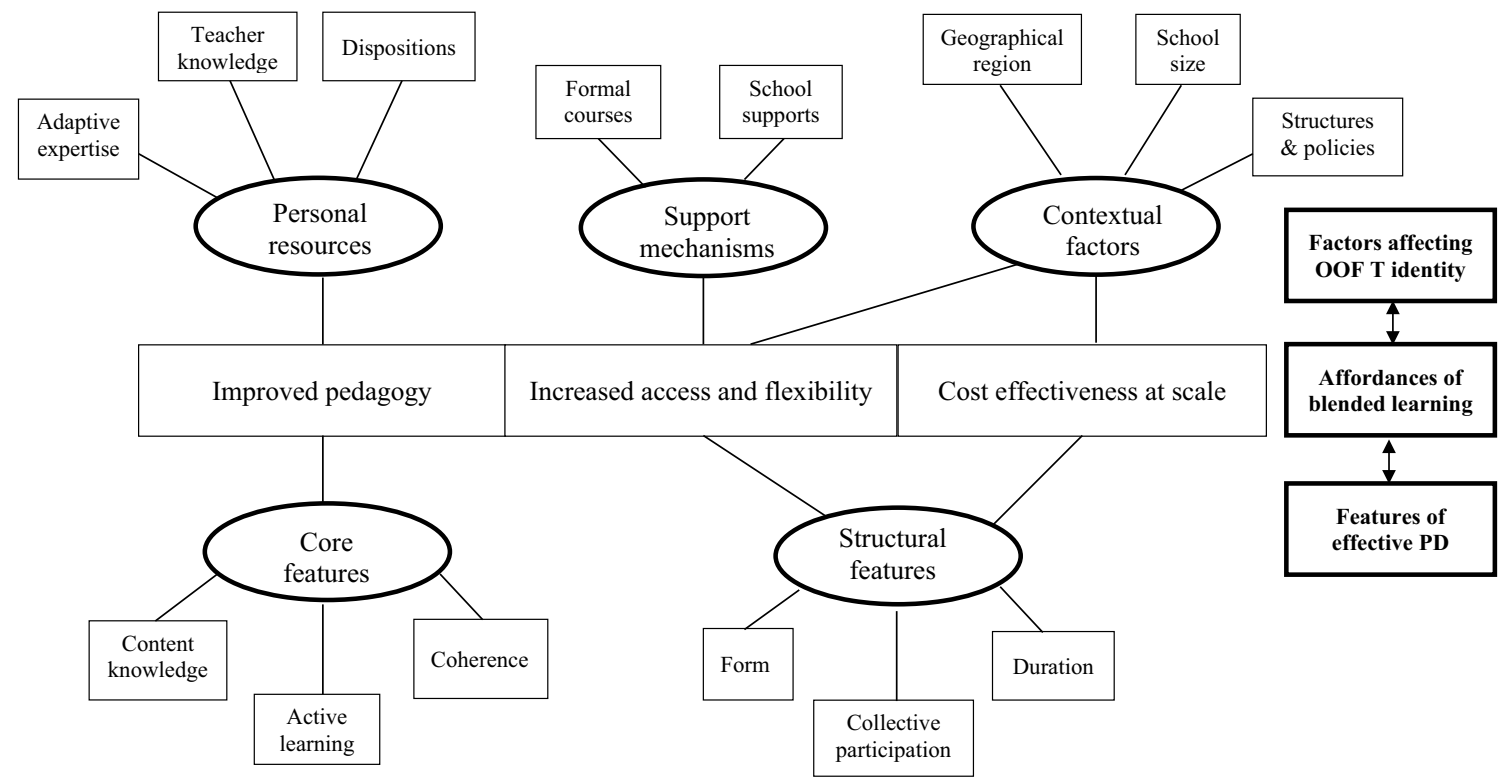

Fig. 2 Contribution of blended learning environment to effective professional learning for out-of-field teachers of mathematics

as dispositions derived from other important factors. Teachers who engage in out-of-field teaching must be willing and have the ability to adapt to new circumstances demanded by moving between and crossing over to the new educational environment of the other subject (mathematics in this case) or in other words have adaptive expertise. As regards teacher knowledge, the PDMT focuses on developing the out-offield teachers' mathematics content knowledge (MCK) and pedagogical content knowledge (PCK). Two considerations dictated this direction: (1) the quantum of mathematics knowledge required by the Teaching Council (60 ECTS credits), and (2) the knowledge that participating teachers already completed the professional educational requirements including general pedagogy for qualified teacher status. Thus, the entire educational focus in the PDMT is on PCK (15 ECTS credits).

\section{Discussion}

We return now to the research question guiding this study: How does a blended learning environment contribute to effective professional learning for out-of-field teachers of mathematics? We framed the question in this way to draw attention to the specific combination of factors influencing design of the blended learning environment, and to situate our study within the existing literature in this field. A particular focus of recent research into online mathematics teacher education involves studying the impact of the interactional environment on teachers' learning. For example, Borba and Llinares (2012), in their introduction to a ZDM issue on this topic, pointed to studies that investigated the formation of teacher professional communities, or changes in teachers' knowledge construction and professional argumentation (Borba \& Llinares, 2012). Our research into the PDMT instead offers a macro-level analysis of the relationship between a blended learning environment and the professional learning needs of a specific population of teachersthose teaching mathematics "out of field", that is, without adequate qualifications to do so. Borba and Llinares referred to the distinctive challenges of designing blended learning environments, and our analysis illustrates how the PDMT addressed the multiple design challenges of reaching a large and geographically dispersed teacher population, combining online and face-to-face program elements, and satisfying policy imperatives in relation to program content in order to produce fully qualified graduates.

To answer our research question, we conceptualised blended learning in terms of boundary crossing between face-to-face and computer-mediated modes of teaching and learning, and we mapped three main affordances of blended learning environments (Graham et al., 2005) onto two frameworks that together define effective professional learning for out-of-field teachers (Garet et al. 2001; Hobbs, 2013). The resulting model is presented in Fig. 2 and elaborated below.

The reasons for using a blended learning environment identified by Graham et al. (2005) align with the core and structural features of the PDMT as a professional development program (Garet et al. 2001) and also with the personal resources, support mechanisms and contextual factors that influence the experiences of out-of-field teachers of mathematics in moving between different disciplinary fields and 
contribute to their evolving identity as in-field teachers of mathematics (Hobbs, 2013). The pedagogical richness of combining face-to-face and online learning builds on participants' personal resources and gives them access to the program's core features. These core features included: attention to developing mathematical and pedagogical content knowledge; active learning and human interaction in mathematics pedagogy workshops and summer schools that were facilitated by expert teachers and teacher educators; and opportunities to adaptively apply their learning by conducting action research in their own classrooms.

The degree of access, flexibility and cost effectiveness at scale afforded by the blended learning environment defines the structural features of the PDMT. The program provides a support mechanism for out-of-field teachers in the form of an extended, university-accredited program that is sensitive to contextual factors such as geographical dispersion and variation in school sizes and infrastructure. The PDMT, as a blended learning program, is not limited by constraints of space and time and is thus accessible "any time, any place" to teachers throughout Ireland.

So far we have been concerned with analysing how the PDMT, as a blended learning program, can help teachers cross the sociocultural boundary between the in-field subject that they are qualified to teach, and the out-of-field subject of mathematics. But when a boundary-crossing perspective is applied to all those involved in the PDMT, we can also identify a set of intersecting practices that cross professional communities and sites. In particular, in the participating higher education institutions we have professional mathematicians (lecturers and tutors) and mathematics teacher educators (lecturers and tutors), and in schools we have outof-field teachers of mathematics (qualified teachers of other subjects) and qualified mathematics teachers. While the goal of the PDMT is to promote successful crossings between the central practices of the out-of-field teacher of mathematics and the qualified mathematics teacher, and identify affordances that facilitate successful crossings between these practices, we may not confine our endeavour only to these two practices. Other boundary-crossings are necessary to implement such a program successfully.

Figure 3 maps intersecting practices that proved important in the evolution of the PDMT, and highlights multiple boundary-crossings between school and higher education institution sites as well as between the practices of mathematicians, mathematics teacher educators, and mathematics teachers. A number of devices, mechanisms and strategies that we now identify as boundary objects were devised and implemented to overcome ideological and operational barriers between actors from different intersecting practices, notably, university mathematics teacher educators and all other practices. For example, the concept of work package proved extremely useful and the partitioning of the entire

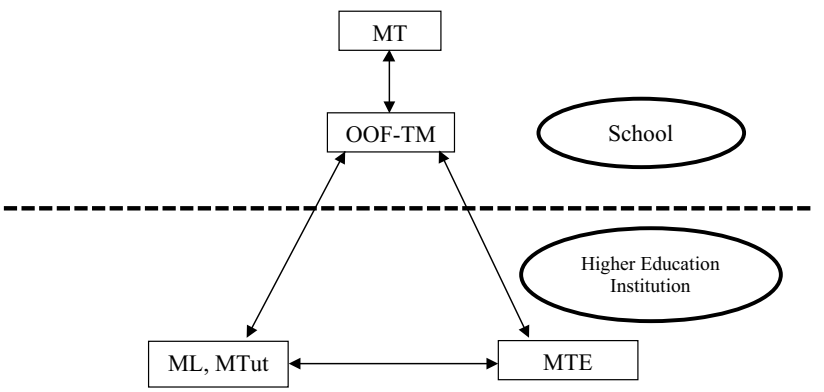

Fig. 3 Intersecting practices related to the PDMT. $M T$ (qualified) mathematics teacher, $O O F-T M$ out-of-field teacher of mathematics, $M L$ mathematics lecturer, MTut mathematics tutor, MTE mathematics teacher educator

program into defined work packages clarified roles and responsibilities of consortium members and personnel, and avoided potential conflict. Additionally, the development of a module booklet for each of the 12 modules detailing the content, structure and sequencing, interactive assignments, assessment and links to post-primary mathematics curriculum established common ground between all parties including the out-of-field teachers.

\section{Conclusion}

The PDMT program evolved in an ill-defined educational environment that was challenging in several respects as regards operationalising the blended learning design. It would require "good enough" (not perfect) solutions to practical problems in real time, and a number of iterations to arrive at better program outcomes in terms of technology, delivery, and academic standards and student support. In broad terms, the design of such a program posed significant challenges in a number of areas: leadership/management; technology; academic; and professional. While it is customary to present conclusions at the end of a study it is difficult in the current circumstances to distinguish between conclusions, insights or lessons learned. However, we will make a small number of tentative conclusions based on our analysis followed by significant insights and lessons learned. A study of significant national undertaking in mathematics education, in this case a national blended learning response to upskilling out-of-field teachers of mathematics in Ireland, is a worthy way to develop practice-based knowledge to serve the wider research community.

Viewed as a curriculum development project, the overall goal was to develop and implement a professional diploma to upskill out-of-field teachers of mathematics. Our experience with the PDMT and analysis show that the program has a number of strengths. The program emphasises mathematics content, and how children learn mathematics. Learner 
engagement is long-duration and intensive among participants, and there is a close alignment with national educational priorities and standards. Nevertheless, we also learned that epistemic considerations can be expected and must be addressed when professional mathematicians engage with school mathematics teachers in curriculum development.

In terms of insights gained and lessons learned, it is obvious now that some issues merited explicit consideration in the program design process at the initial design stage. For example, the nature of blended learning deserved more attention because a better appreciation could lead to better learning opportunities and outcomes for teachers. On the other hand, the absence of an explicit guiding definition of blended learning at the outset proved a considerable advantage for the course designers as an implicit operational definition directed all attention and resources to achieving a purposeful blend of face-to-face and computer-mediated modalities.

As the program evolved over the years, several new practices and innovations were introduced, drawing on the capacity of blended learning to improve the learning environment and program delivery. During this period, it became obvious that the program implementation relied heavily on what we now refer to as boundary crossing. The term boundarycrossing was first used to describe how professionals in work situations functioned in areas where they were largely unqualified to achieve their work goals (Akkerman \& Bakker, 2011). The concept has evolved to include boundaries between communities, practices, disciplines, and activity systems, and is therefore appropriate for studying a complex professional learning program like the PDMT.

Our analysis of the PDMT drew on three perspectives on boundary crossing: the perspective of the out-of-field teacher moving between different disciplinary fields, the perspective of those who designed and taught in the program and negotiated discontinuities between the practices of mathematics and mathematics education, and the blended learning perspective that coordinates face-to-face and computermediated teaching and learning. The original contribution made by our study is to map the affordances of the blended learning environment onto two frameworks that illuminate the professional development needs of out-of-field teachers and the characteristics of effective professional development programs. Borba and Llinares (2012) noted the increasing influence of social theories of learning in research into online technologies for mathematics teacher education, mainly through an emphasis on how technology mediates discourse and collaboration between teachers. Theorising the blended learning design of the PDMT in terms of boundary crossing adds a new dimension to this body of research.

Finally, viewing the PDMT through these multiple lenses suggests additional refinements for future developments. More should be made of the potential of blended learning to build an active learning environment across frameworks including all activities and formats to promote subject matter and PCK learning. The boundary-crossing lens also brings into focus a role for professional learning communities that were not evident in the PDMT. While this was not addressed in the design and implementation of the PDMT, it remains to be seen whether the capacity and infrastructure exists in the system to incorporate it into a national upskilling program such as the PDMT.

The three theoretical frameworks applied in this paper have helped to elucidate the emergent, signature features of the PDMT blended learning design, and illustrate how these have enabled the PDMT to achieve impact on teachers' knowledge at a national scale in Ireland. The PDMT stands as an exemplar model for supporting CPD-specifically in mathematics teacher education - and the deployment of blended learning to mediate a programme of teacher upskilling with systemic, national impact.

Acknowledgements The PDMT is a DES funded project. We thank the Minister and his officials in the Professional Development Section for Teachers of the DES for their ongoing support through the PDMT Monitoring Group. We wish to thank the many colleagues, agencies and institutions including Google (Ireland), who made this project possible. We acknowledge the contribution of all consortium members to the success of the project including several former staff members at the National Centre including Drs. Miriam Liston, Lisa O'Keeffe, Fiona Faulkner and Ms. Aoife Smith who contributed to the design, development and implementation of the program in various roles. Various departments in the University of Limerick, in particular the ITD department, and the coordinating group in EPI*STEM supported by several National Program Coordinators made important contributions to the success of the PDMT.

\section{References}

Akkerman, S., \& Bakker, A. (2011). Boundary crossing and boundary objects. Review of Educational Research, 81, 132-169.

Alammary, A., Sheard, J., \& Carbone, A. (2014). Blended learning in higher education: Three different design approaches. Australasian Journal of Educational Technology, 30(4), 440-454.

Ball, D. L., Thames, M. H., \& Phelps, G. C. (2008). Content knowledge for teaching: What makes it special? Journal of Teacher Education, 59(5), 389-407.

Borba, M., Askar, P., Engelbrecht, J., Gadanidis, G., Llinares, S., \& Aguilar, M. (2016). Blended learning, e-learning and mobile learning in mathematics education. ZDM Mathematics Education, 48, 589-610.

Borba, M., \& Llinares, S. (2012). Online mathematics teacher education: Overview of an emergent field of research. ZDM Mathematics Education, 44, 697-704.

Borko, H., Whitcomb, J., \& Liston, D. (2009). Wicked problems and other thoughts on issues of technology and teacher learning. Journal of Teacher Education, 60(1), 3-7.

Cosgrove, J., Shiel, G., Oldham, E., \& Sofroniou, N. (2004). A survey of mathematics teachers in Ireland. Irish Journal of Education, $35,20-44$.

du Plessis, A. E. (2015). Effective education: Conceptualising the meaning of out-of-field teaching practices for teachers, teacher 
quality and school leaders. International Journal of Educational Research, 72(Suppl C), 89-102.

du Plessis, A. E. (2016). Leading teachers through the storm: Looking beyond the numbers and turning the implications of out-of-field teaching practices into positive challenges. International Journal of Educational Research, 79, 42-51.

Faulkner, F., Kenny, J., Campbell, C., \& Crisan, C. (2019). Teacher learning and continuous professional development. In L. Hobbs \& G. Törner (Eds.), Examining the phenomenon of "teaching out-offield": International perspectives on teaching as a non-specialist (pp. 278-318). Singapore: Springer Nature.

Faulkner, F., \& O' Meara, N. (2018). Professional development for out-of-field post-primary teachers of mathematics: A pre and post analysis of the impact of mathematics specific pedagogical training. In Paper presented at OOF-TAS Symposium, Bolzano, Italy, 2-3 September.

Garet, M., Porter, A., Desimone, L., Birman, B., \& Yoon, K. S. (2001). What makes professional development effective? Results from a national sample of teachers. American Educational Research Journal, 38(4), 915-945.

Goos, M., Ní Ríordáin, M., Lane, C., \& Faulkner, F. (2019). Impact of a national professional development program on the beliefs and practices of out-of-field teachers of mathematics. In G. Hine, S. Blackley, \& A. Cooke (Eds.), Mathematics education research: Impacting practice, Proceedings of the 42nd annual conference of the Mathematics Education Research Group of Australasia (pp. 316-323). Perth: MERGA.

Graham, C. R. (2006). Blended learning systems: Definition, current trends, and future directions. In C. J. Bonk \& C. R. Graham (Eds.), The handbook of blended learning: Global perspectives, local designs (pp. 3-21). San Francisco: Pfeiffer.

Graham, C. R. (2013). Emerging practice and research in blended learning. In M. G. Moore (Ed.), Handbook of distance education (3rd ed., pp. 333-350). New York: Routledge.

Graham, C. R., Allen, S., \& Ure, D. (2005). Benefits and challenges of blended learning environments. In M. Khosrow-Pour (Ed.), Encyclopedia of information science and technology (pp. 253-259). Hershey, PA: Idea Group.

Heid, M. K., Wilson, P. S., \& Blume, G. W. (Eds.). (2015). Mathematical understanding for secondary teaching: A framework and classroom-based situations. Charlotte, NC: Information Age Publishing.

Hobbs, L. (2013). Teaching 'out-of-field' as a boundary-crossing event: Factors shaping teacher identity. International Journal of Science and Mathematics Education, 11(2), 271-297.

Hobbs, L., \& Törner, G. (Eds.). (2019). Examining the phenomenon of "teaching out-of-field": International perspectives on teaching as a non-specialist. Singapore: Springer Nature.

Ingersoll, R. M. (2002). Out-of-field teaching, educational inequality and the organization of schools: An exploratory analysis. Seattle, WA: University of Washington, Center for the Study of Teaching and Policy.

Lane, C., \& Ní Ríordáin, M. (2019). Out-of-field mathematics teachers' beliefs and practices: An examination of change and tensions using Zone theory. International Journal of Science and Mathematics Education. https://doi.org/10.1007/s10763-019-09964-5.

McKenney, S. (2018). How can the learning sciences (better) impact policy and practice? Journal of the Learning Sciences, 27(1), 1-7. https://doi.org/10.1080/10508406.2017.1404404.

Ní Ríordáin, M., \& Hannigan, A. (2009). Out-of-field teaching in postprimary mathematics education: An analysis of the Irish context. Limerick, Ireland: NCE-MSTL. Retrieved from http://epistem.ie/ wp-content/uploads/2015/04/Out-of-field-teaching-in-post-prima ry-Maths-Education.pdf.

Ní Ríordáin, M., Paolucci, C., \& O’ Dwyer, L. M. (2017). An examination of the professional development needs of out-of-field mathematics teachers. Teaching and Teacher Education, 64, 162-174.

Osguthorpe, R., \& Graham, C. (2003). Blended learning environments: Definitions and directions. The Quarterly Review of Distance Education, 4(3), 227-233.

Penuel, W. R. (2015). Infrastructuring as a practice for promoting transformation and equity in design-based implementation research. Keynote address presented at the 11th Annual International Conference of the International Society for Design and Development in Education (ISDDE), University of Colorado, Boulder, CO. Retrieved September 22, 2015, from http://learndbir.org/talks -and-papers/infrastructuring-as-a-practice-for-promoting-trans formation-and-equity-in-design-based-implementation-resea rch-2015.

Penuel, W. R. (2019). Co-design as infrastructuring with attention to power: Building collective capacity for equitable teaching and learning through design-based implementation research. In J. Pieters, J. Voogt, \& N. Pareja Roblin (Eds.), Collaborative curriculum design: Sustainable curriculum innovation and teacher learning (pp. 387-401). Cham: Springer. https://doi.org/10.1007/978-3030-20062-6_21.

Rowland, T., Huckstep, P., \& Thwaites, A. (2005). Elementary teachers' mathematics subject knowledge: The knowledge quartet and the case of Naomi. Journal of Mathematics Teacher Education, $8(3), 255-281$.

Shulman, L. S. (1986). Those who understand: Knowledge growth in teaching. Educational Researcher, 15(2), 4-31.

Star, S. L., \& Griesemer, J. R. (1989). Institutional ecology, "translations" and boundary objects: Amateurs and professionals in Berkeley's Museum of Vertebrate Zoology, 1907-39. Social Studies of Science, 19, 387-420.

The Teaching Council (2009). General and special requirements for teachers of recognised subjects in mainstream post-primary education.

Publisher's Note Springer Nature remains neutral with regard to jurisdictional claims in published maps and institutional affiliations. 